\title{
35
}

\section{Indicators for the Evaluation of Organizational Performance}

\author{
Gert Zülch, Thomas Grobel, Uwe Jonsson
}

ifab - Institute of Human and Industrial Engineering (Institut für Arbeitswissenschaft und Betriebsorganisation), University of Karlsruhe, D-76128 Karlsruhe, Kaiserstraße 12, Germany.

\begin{abstract}
Due to increasing international competition, productive enterprises are currently searching for measures to improve their order processing. As the major potentialities for further improvements are strongly connected to the organization of production systems, the organizational performance has to be investigated and evaluated.

The following paper presents four different approaches for evaluating the organizational performance and for revealing potentialities for improvements, namely: controlling, branch comparison, benchmarking and simulation. Based on a comparison of these approaches, a conceptive concept for evaluation will be developed.

Considering certain prerequisites, four measures are defined in the shape of degrees of goal achievement. Such degrees of goal achievement compare the real performance of a production system to a theoretically optimal performance. The four measures refer to lead time, due-date dependability, utilization and work in progress of a production system.

The concept for evaluation is connected to a simulation-aided approach in order to improve the organizational performance. This concept is demonstrated by using a case study of an enterprise of mechanical engineering as an example. The case study is performed with the simulation tool FEMOS and results in a proposal for the reorganization of the departments for design and operations planning.
\end{abstract}

\section{NEED FOR INDICATORS}

In order to maintain their competitiveness, productive enterprises have to estimate their position in the market compared to competitors on one hand. On the other hand they must search for approaches to improve their over-all performance in order to stay in the market.

Thereby, the organization of order processing becomes a dominating influence on performance, as technical means which might be used to support the performance of certain tasks are insufficient to meet all requirements $[1$, p. $133 \mathrm{ff}$.]. Regarding the order processing, it is of special interest to reveal possibilities for an improvement and to quantify potentialities by all possible means.

In order to evaluate the quality and discover such potentialities of an organizational structure, special indicators can be used. In the following, different approaches to evaluate the organizational performance will be presented. Afterwards, an adequate concept for the registration of relevant aspects of organizational performance will be developed.

\section{DIFFERENT METHODS TO REVEAL POTENTIALITIES FOR IMPROVEMENTS}

The revelation of improvement potentialities is a major topic for every company, and therefore a wide range of methods have been developed. A feasable approach for their classification is the distinction of various sets of solutions which are systematically taken into consideration by these methods. In figure 1 the methods are divided into four classes "controlling", "branch 
comparision", "benchmarking" and "simulation". Before selecting one method, the characteristics of these classes will be described.

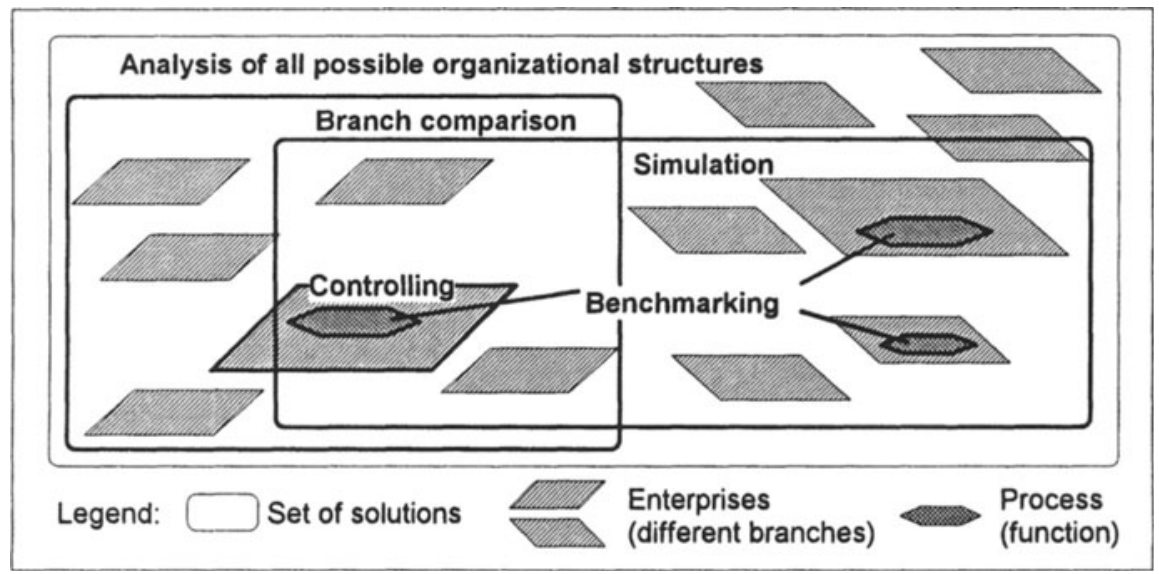

Fig. 1: Solution sets of different methods to reveal potentialities of improvement

\section{Controlling}

The most common way to gain improvement potentialities is the performance measurement of the production system under investigation, usually performed by pre-defined indicators. This method is relatively easy to perform and the procedure of measurement is well-known. But because of the missing possibility of a comparison to other enterprises the systematic search for better solutions is rather limited. Often, the only available data for comparison is derived from preceeding measurements and improvements are made, more or less against an empirical background. Therefore, controlling relates only to one special set of solutions, respectively one single company. A direct comparison of indicators to other enterprises is nearly impossible, unless the organizational structure standing behind is known as simlar and comparable.

An approach to overcome the described deficits is the comparison of the indicators to a theoretical optimum. Although this may lead to more distinctive key data the definition of the theoretical optimal values turns out to be a problem.

\section{Branch comparison}

For decades, there already has existed another possibility with which to compare the situation of one enterprise to that of other companies working in the same economic branch. This is the comparison of typical economic and logistic characteristics with mean values achieved by other productive enterprises within this branch. These data is based on inquiries which are usually initiated by industry associations (i.e. [2]).

But obviously, this approach bears a certain disadvantage. Even if the averages of the reported characteristics are enhanced by their standard deviations, the reason for a difference between the values of one company and those of the whole branch can hardly be discovered. Such proof demands a detailed description of the underlying organizational structures which certainly influence the values on both sides, whereas this data is usually not available.

\section{Benchmarking}

When comparing existing production systems by using comparable key data, e.g. the measured performance time of a standardized task, distinctively transferable results, which may lead 
directly to potentialities of improvement, can be achieved. Unfortunately, suitable companies for such a comparison are usually competitors on the market, and therefore their willingness to take part in an analysis and disclose their internal data is, in practice, a great obstacle.

Therefore, another approach has been established using the term "benchmarking" that avoids the mentioned problem by comparing only certain processes or sub-units of companies (cf. [3]). The aim is to recognize a process or sub-unit in another company that represents best practice in the fulfillment of the assigned task and then to improve the own process or sub-unit according to this "best of class".

By referring only to sub-units, also non-competing companies can take part in a benchmarking analysis and learn from each other. Nevertheless, gathering the required data and its adequate evaluation is in many cases a great burden within the benchmarking process.

In figure 1 this approach is represented by its set of possible solutions. This set includes all real existing systems and in addition all solutions that are reachable by combining existing processes or sub-units.

\section{Simulation}

The major problem of the preceeding methods is that they are based only on existing systems and thereby only seldom reveal organizational solutions which are really new. This is related to the need of proving the economic value of a new solution, before it is realized. For solving this problem, a model of the real system has to be be built which allows the prediction of the system's behaviour by simulating its dynamic flow of events. In a simulation based analysis the processes inside the production system can be tracked in detail and different approaches of improvement can be tried without any monetary risk.

Of course, the expressiveness of a simulation based analysis depends strongly on the quality of the used model, which has to be built very carefully by experienced personnel. But this effort is justified by the great potential usage of such an analysis. Achieveable solutions of existing systems dominate the benchmarking approach. On the other hand, a simulation based analysis can, potentially, consider every possible solution.

In practice, the set of possible solutions is limited by the features of the simulation tool. In figure 1 the simulation approach is represented by a subset of all possible solutions. But nevertheless, the solution set of simulation is much wider than the set of benchmarking.

\section{CONCEPT FOR THE EVALUATION OF THE ORGANIZATIONAL PERFORMANCE}

Regardless what specific method is applied for evaluating the organizational performance, an evaluation and a comparison of different systems is performed by quantifying a certain set of measures. The definition of measures has to be based on a suitable model and has to be embedded in a comprehensive system's concept (cf. $[4$, p. 260]). Such a concept will be presented in the following section (cf. [5, p. $82 \mathrm{ff}$.]).

\subsection{Conceptual Frame}

When evaluating a system's behaviour, this system has to be marked off by a definition of its system boundaries (cf. fig. 2). Herewith, the evaluation has to take into consideration all relevant influences on this system. As the organizational performance regards the winding-up of orders, the system boundaries can be fixed with the order entry in the production system and the finish of the last step of the processing of the order.

Due to these boundaries, measures can be divided into exogene and endogene measures (cf. e.g. $[6$, p. $36 ; 7$, p. 330]). Exogene measures quantify the relation between system and environment and can be designated as market goals, as they are related to orders. The endogene measures describe the behaviour of the resources within the system and are also named as cost goals (cf. e.g. [4, p. 2]).

In order to get a deeper insight into the system's behaviour it is insufficient to quantify goal achievement only by a mean value. Besides measures with the character of a mean value, such 
measures should additionally be applied for a complete description of all effects, which quantify the variation from the mean values (cf. [5, p. $55 \mathrm{ff}$.]; for example cf. $[8$, p. 726; 9, p. 53]). This differentiation of key data between mean values and deviations implies their independency.

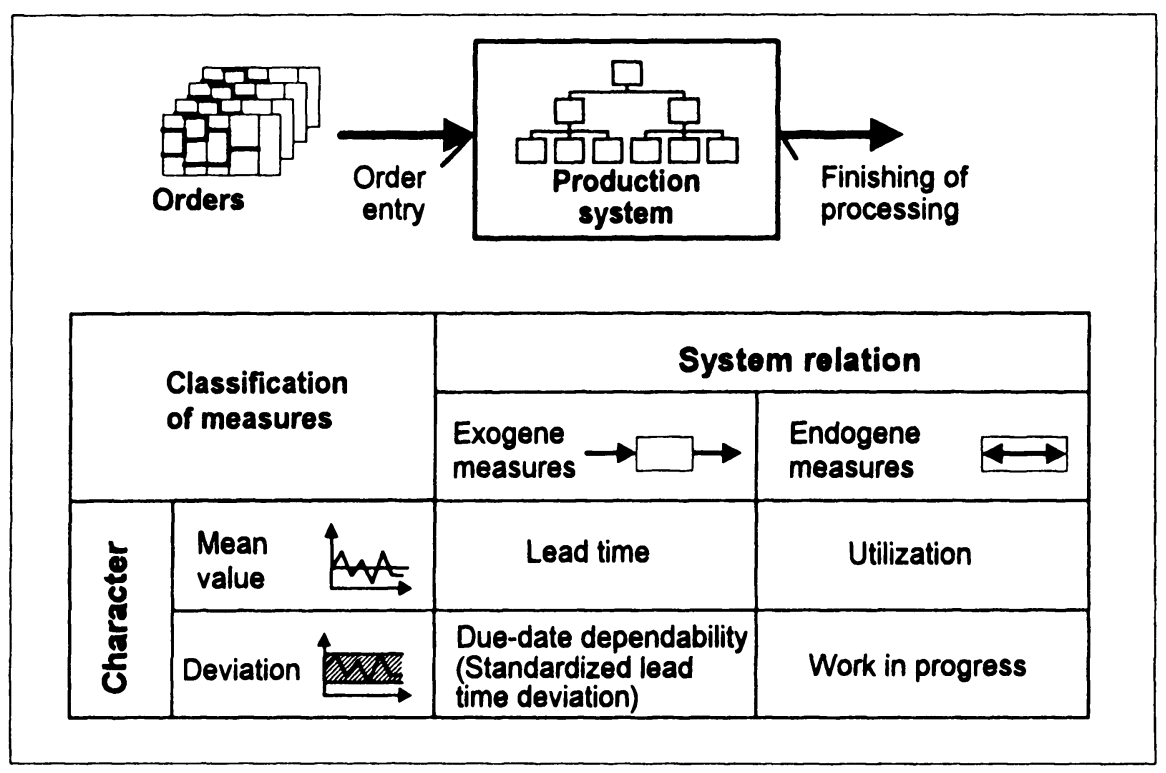

Fig. 2: Conceptual frame for the evaluation (following $[5, \mathrm{p} .83]$ )

\subsection{Selection of Measures}

Following this idea, the concept of evaluation has to hold four different measures. For the evaluation of the organizational performance, the logistic key data utilization, work in progress, lead time and due-date dependability are regularly applied (cf. e.g. [10, p. $8 \mathrm{ff}$.]). Supposing that there is a suitable definition, these measures can be integrated into the conceptual frame which has been introduced in the previous chapter (see fig. 2).

Lead time and due-date dependability quantify the quality of order processing and therefore are exogene measures. Utilization and work in progress are endogene measures and cover the use of the resources of the production system. Lead time and utilization can be characterized as mean values, while due-date dependability and work in progress signify the deviation from the respective average. The due-date dependability worsens with an increasing deviation of the lead times of orders; the work in progress increases, if the utilization varies predominantly over time.

A major problem connected to the use of these logistic indicators is the fact that no generally accepted definition for the quantification of the due-date dependability is available (cf. [11, p. 1093]). Furthermore, a dependancy often exists between lead time and due-date dependability, as long lead times imply poor due-date dependability. Therefore, this key indicator does not contain additional information for a logistic evaluation.

As a consequence, the due-date dependability has to be replaced by a suitable measure. This measure should be independant from a pre-defined due-date and independent from lead time (cf. also the approaches of $[12$, p. $322 ; 13$, p. $78 ; 14$, p. 592]). Such a measure will be defined in the following chapter using the standardized lead time deviation. 


\subsection{Definition of the Measures}

When defining the measures used in a concept for evaluation, some requirements have to be met. In order to simplify the interpretation of results, the measures should be standardized and monotonous (cf. [15, p. 287 f.; 16, p. 20]). The definition should be dimensionless and imply a uniform range of value. An increasing value should quantify an increasing approximation to an ideal state.

In order to fulfill these prerequisites, so-called degrees of goal achievement have proven to be a suitable approach (cf. [4, p. $69 \mathrm{ff} ; 17$, p. $133 \mathrm{ff}$.$] ). Degrees of goal achievement relate the$ performance of a system to a theoretically optimal performance. If the optimal performance is achieved, the value of the degree of goal achievement will be $100 \%$.

Due to the conceptual frame developed above, the concept for evaluation consists of four different measures. These measures are the degrees of goal achievement of lead time, of standardized lead time deviation, of utilization of the organizational units and of work in progress (measured as demanded capacity). In contrary to most of the available concepts, these measures are independent because of an appropriate definition. Below, the different measures will be defined and explained (for a detailed description see [5, p. 82 ff.]; for other approaches cf. e.g. [4, p. $70 \mathrm{ff}$; 18, p. $96 \mathrm{ff}$.])

As a measure for lead time the degree of goal achievement of lead time degree $(G L T)$ will be used which represents the average lead time degree of all the processed orders of a system within a certain period. The lead time degree $L T D$ of an order $k$ is calculated by a division of the minimal theoretical lead time $M L T$ with the real resp. simulated lead time $R L T$ :

$$
L T D_{k}=\frac{M L T_{k}}{R L T_{k}}
$$

The lead time of an order is defined as the time needed to process an order from order entry until delivery (the finishing of the last step of order processing). The minimal lead time of an order can be calculated based on the function network which represents an order (cf. $[19, \mathrm{p}$. 181]). A function network consists of all steps and their relations needed to process an order. The minimal lead time of an order equals the length of the critical path in this function network when exclusively processing and transportation times are considered (cf. [20, p. $15 \mathrm{ff}$.]).

When using degrees of goal achievement, some authors define due-date dependability using a date which is calculated directly dependent on the minimal lead time of an order (cf. e.g. the approaches of $[4$, p. $70 ; 18$, p. 100]). As a consequence, low values of a lead time degree imply a low value of the due-date dependability.

In order to avoid such a dependancy, a standardized lead time deviation is used here which quantifies the variation of the lead times based on the average lead time instead of on the minimal lead time. For that purpose, a corrected calculated lead time is used. This corrected calculated lead time can be achieved, if the minimal lead time of an order is elongated by an average prolongation factor of the orders. This factor can be calculated as the reciprocal value of the degree of goal achievement of lead time degree. Following this line of reasoning, the standardized lead time deviation $S L D$ for an order $k$ can be calculated by comparing the corrected calculated lead time with the deviation of real lead time from this corrected lead time:

$$
S L D_{k}=\frac{R L T_{k}-\frac{M L T_{k}}{G L T}}{\frac{M L T_{k}}{G L T}}=\frac{R L T_{k}}{M L K_{k}} \cdot G L T-1 .
$$

As the optimal value of the standardized lead time deviation equals zero, a transformation for the calculation of the degree of standardized lead time deviation DSL has to be performed. As earliness should be equally considered to delay, the absolute value of SLD is used:

$$
D S L_{k}=\frac{1}{1+\left|S L D_{k}\right|} \text {. }
$$


The degree of goal achievement of the standardized lead time deviation is calculated similar to the degree of goal achievement of lead time degree as an average value considering all finished orders.

The utilization of a production system quantifies the mean use of the capacity within a certain period. In order to calculate a degree of goal achievement of utilization the theoretical capacity stock is compared to the amount of capacity processed during the period of evaluation. The processed capacity covers set-up and processing time of all processed orders.

In order to evaluate the organizational performance, the work in progress has to be calculated in relation to the capacity stock of orders processed in the system. The work in progress gives an impression of the average capacity of the waiting orders. As minimal value a minimal work in progress can be defined which considers the fact that the orders have to be at least within the system when they are processed (cf. [4, p. $77 \mathrm{ff}$.]). In order to quantify the degree of goal achievement of work in progress GWP, this minimal work in progress MWP is compared to the average waiting amount of capacity $W A C$ :

$$
G W P=\frac{M W P}{M W P+W A C} .
$$

The concept presented here follows the idea of comparing the system's behaviour with a theoretically optimal system. This approach was already used with connection to the simulation tool FEMOS in order to reveal and compare different solutions for the organizational design of several production systems [ $5, \mathrm{p} .166 \mathrm{ff}$.]. This procedure will be demonstrated here using an enterprise of mechanical engineering as an example.

\section{EVALUATION OF AN ENTERPRISE OF MECHANICAL ENGINEERING}

This case study treats a middle-sized enterprise of mechanical engineering which is a located in the South-West of Germany. The enterprise has about 270 employees and a turnover of about 60 Mio DM. 200 persons were employed in parts production and assembly, the remaining number in the pre-productive sectors such as design, operations planning and sales.

\subsection{Production Situation}

The enterprise produced components for material flow automation, e.g. conveyor belts and devices for machine interlinkages. The product spectrum consisted mainly of more or less standardized components, which were tailor-made to customer specifications. A customer order regularly covered a complete conveying system consisting of various components. Each system had to be planned and realized considering the special production environment of the customer, in particular with regard to the layout of the production system and the interfaces of the existing machines. Therefore, the production situation of this enterprise could be characterized as a specialized production with a strong customer-orientation.

The enterprise was traditionally organized according to functions. Basically it consisted of the following organizational units: the sales department, the purchase department, the design department, the department of operations planning and scheduling, parts production and assembly and the shipping section.

The winding-up of orders could be described as follows: Starting from a request the sales department run the negotiations with the customer. After order entry, the design department developed the drawings of the complete system and its components. The purchase parts were ordered by the purchase department. The operations planning and scheduling could be initiated, if the construction drawings and bill-of-materials were completed. Supplied by job papers and wiring design, parts production and assembly could start subsequently. After a final control the conveying system was delivered and assembled at the customer's site.

The major problem of the enterprise was its reliability to delivery dates promised to the customer, as overlapping of this date caused conventional penalties. Compliance with due dates proved rather difficult, as the capacity of the workshops was loaded at a relatively high rate. The existing organizational structure did not allow any immediate reaction to the customer's desires 
for a change in the product design, for example, if the customer wanted to change the layout of the conveying system after order delivery.

\subsection{The Simulation Tool FEMOS}

The evaluation concept was realized and applied in connection with the simulation tool FEMOS for a systematical analysis of the influences on the organization of production systems (cf. $[5 ; 21])$. FEMOS has been developed for the analysis such systems at the ifab-institute of the University of Karlsruhe since 1988. It has been successfully applied solving various types of problems in real production systems (see e.g. $[1 ; 17 ; 19$, p. $177 \mathrm{ff}$.; 22]). In these applications e.g. the shaping of the organizational structure of production systems, structuring of workshops and strategies of production control were analyzed supported by the FEMOS-program (cf. e.g. [23]).

The simulation tool can be characterized by an organization-oriented approach. The model which the program is based upon, allows the differentiation between personnel and work places on one hand and the condensation of different workplaces to departments on the other hand. Furthermore, sophisticated levels of the capabilities of a department's personnel can be considered. Orders are described by function networks. Thus, parallel processing of different functions can be modelled rather easily.

\subsection{Evaluation of the Initial Situation}

In order to analyze and develop approaches for organizational improvements, the enterprise was modelled with the simulation tool FEMOS. As the organization of parts production and preassembly were not to be changed, the study concentrated on the pre-productive functions. Parts production and pre-assembly were treated in the following discussion as a black box with fixed lead times.

Using the order entry to the design department and the delivery to the shipping department as system boundaries, nine steps of order processing could be identified: After checking the material need, the construction drawings and bill-of-materials for the various components were created and the switches and motors had to be selected. Based on this information, the electronic design could be performed for the entire conveying system. The last steps of the order processing in the pre-productive sector were the creation and the electronic documentation of the job papers. Parts production and assembly were treated as black box with fixed lead times. These steps had to be performed for all of the orders which combined various, more or less, standardized components (cf. the example in fig. 3).

In order to control the variety of components, 40 product groups were defined, such as different types of chain conveyers, auto guided vehicles, delivery stations and line portals. These groups could be characterized by equal function networks and similar work contents for the different functions.

Based on these product groups, for the simulation study 143 orders of 50 different order types were considered. The order types covered the complexity of the orders processed during the one year, on which the simulation study was based on, and varied from orders enclosing just single components, up to entire conveying systems.

In the initial situation, 26 employees of the pre-productive functions were considered in the simulation study. Six groups of mechanical designers with three to five members are specialized for different product groups. A seventh group of designers with three members performed the electronic design. The first group of two groups of operations planners was responsible for the documentation of components, the other created the job papers. All considered groups, including the department of electronic design, worked without direct linkage to the customer order. Hence, a customer order was processed in different departments of mechanical design and all orders passed the departments of operations planning. 


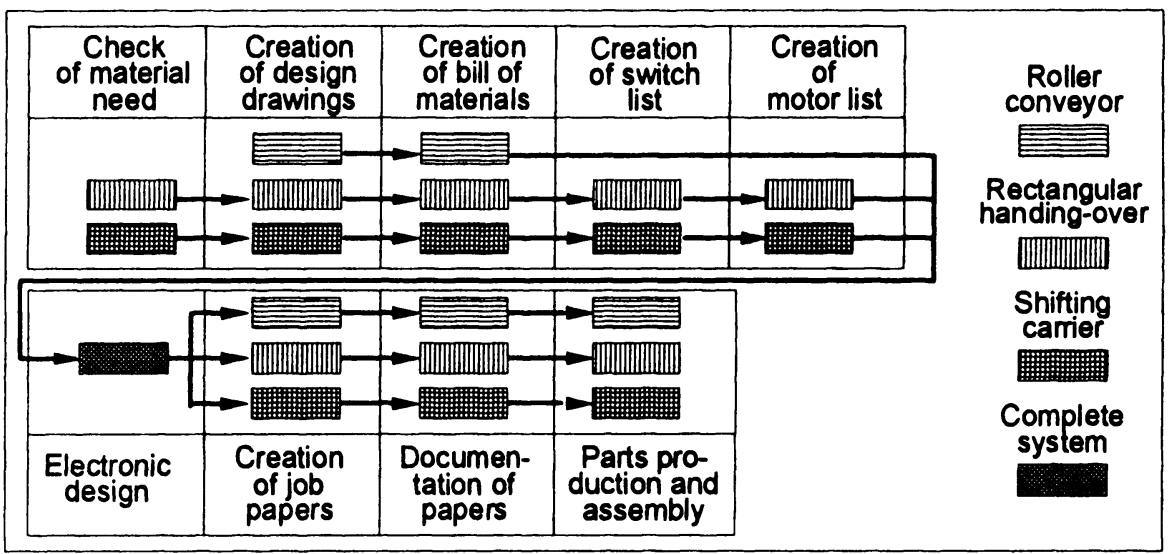

Fig. 3: Example of a function network for a customer order

Based on this data, the initial situation was analyzed with the FEMOS program. In order to assure the validity of the model, the results of a first simulation run concerning the existing system were compared to the values derivated from the real system. As the results revealed the lead times and the utilization of the personnel as comparable to the real system, the validity of the model of the initial situation could be stated: The average lead time of the orders was $\mathbf{8 0}$ days, with a standard deviation of 64 days. A specific characteristic was the remarkable variation of the dynamic utilization of the different design groups, where - similar to the real situation values between $67 \%$ and $92 \%$ could be measured.

When analyzing the degrees of goal achievement (cf. fig. 4), the major problems of the initial situation and potentialities for improvements could be identified. The utilization of the system was not too bad, because about $80 \%$ of the theoretical capacity of the system was used. This value equals the dynamic capacity which can be normally achieved using a functional structure of a production system (cf. [5, p. 137]). The value of the dynamic capacity is always below $100 \%$, as in every real production system disturbances occur due to dependencies of order processing.

\begin{tabular}{|c|c|c|c|}
\hline Criteria & Measure & Unit & Value \\
\hline $\begin{array}{l}\text { Lead } \\
\text { time }\end{array}$ & $\begin{array}{l}\text { Simulated lead time (average) } \\
\text { Theoretical lead time (average) } \\
\text { Degree of goal achievement of lead time }\end{array}$ & $\begin{array}{l}\text { Time units } \\
\text { Time units } \\
\%\end{array}$ & $\begin{array}{r}37.523 \\
14.071 \\
35,7\end{array}$ \\
\hline $\begin{array}{l}\text { Lead time } \\
\text { deviation }\end{array}$ & $\begin{array}{l}\text { Average prologation factor } \\
\text { Degree of goal achievement of lead time deviation }\end{array}$ & $\%$ & $\begin{array}{l}2,80 \\
66,1\end{array}$ \\
\hline Utilization & $\begin{array}{l}\text { Capacity processed } \\
\text { Theoretical capacity } \\
\text { Degree of goal achievement of utilization }\end{array}$ & $\begin{array}{c}\text { Time units } \\
\text { Time units } \\
\%\end{array}$ & $\begin{array}{r}3,99 \cdot 10^{6} \\
4,99 \cdot 10^{6} \\
80,0\end{array}$ \\
\hline $\begin{array}{l}\text { Work in } \\
\text { progress }\end{array}$ & $\begin{array}{l}\text { Minimal work in progress } \\
\text { Simulated work in progress } \\
\text { Degree of goal achievement of work in progress }\end{array}$ & $\begin{array}{l}\text { Time units } \\
\text { Time units } \\
\%\end{array}$ & $\begin{array}{r}8,3 \cdot 10^{6} \\
26,1 \cdot 10^{6} \\
24,2\end{array}$ \\
\hline
\end{tabular}

Fig. 4: Results of the simulation of the initial situation

The value of the standardized lead time deviation indicated that the orders are late in a controlled and regular manner. All orders had more or less the same deviation from the ideal lead time. Based on this fact, it was possible to predict due dates with a certain reliability. The pro- 
blem of the enterprise with its fixing of due dates was not caused by a high deviation of lead times but by long lead times themselves. As a consequence, attempts for major improvements should focus on a general reduction of lead times. The values of the other degrees of goal achievement gave hints for such improvements. The value of the lead time degree was as poor as the degree of work in progress. Thus, as a subject for further improvements the departmental organization could be identified, because its traditional functional orientation was responsible for high lead times and work in progress.

\subsection{Development of Suitable Solutions}

A possible reorganization was analyzed with four different variations. The first idea was to organize the functions following the mechanical design in a more order-oriented way. Therefore, operations planning and electronic design were condensed into one department that performed all the functions for an entire customer order. In order to realize flexible and small units, this new order centre was divided into three sub-units which treat different order types, but was able to process all of the components.

In the second variation, the idea of order-orientation was enlarged: The six design groups were replaced by three groups which were structured according to the order centres of the electronic designers and the operation planners.

Among the arriving orders there were occasionally some that comprise the production of a complete conveying system. Such orders tied up the capacity over a long time. In order to achieve a clearer division of the regular business with such projects, a special project group was installed in the third variation. This group consisted of five designers and two persons for operations planning.

The last variation was assumed to be the most flexible one. The division between designers and personnel for operations planning was abandoned. Each person had to perform all tasks allocated to the respective order centre. This measure implied a higher education and enlarged capabilities of the personnel, especially of those persons who performed the documentation of the papers in the initial situation. For economic reasons, the total number of persons could be reduced by one compared to the other solutions.

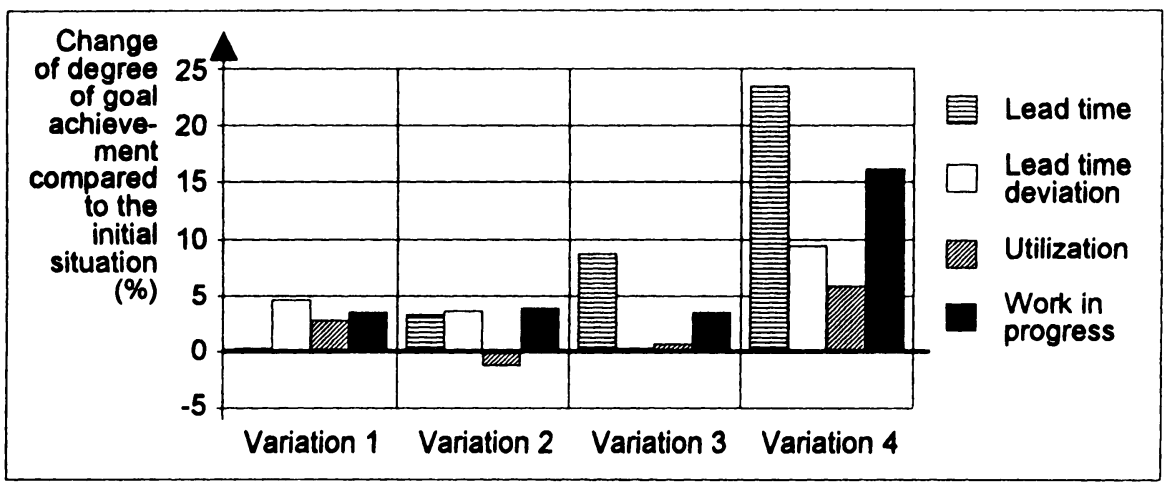

Fig. 5: Results of the simulation study

Regarding the simulation results of the different variations, probable effects revealed. Figure 5 shows the change of the degree of goal achievement for the planning solutions mentioned above when compared to the original situation. According to the simulation results, only minor improvements concerning the degrees of goal achievement can be forecasted when restricted organizational measures as in variation 1 or 2 should be realized. All changes of the values are smaller 
than $5 \%$. That means, the behaviour of the system cannot be approximated significantly towards an ideal state.

This situation changes with the introduction of a specialized organizational unit for the processing of projects. This measure allows to increase the transparency of the entire order processing, as such large orders cause bottlenecks. If a small unit of, say, just a few design engineers is occupied with a large project, it is not able to process other orders which could be wound-up quickly. The project itself is processed comparatively slowly, as too few persons are working on it. As a consequence, the bottleneck would exist over a long time.

Without any doubt the best results are achieved by the most flexible solution which implies an equal level of capabilities of all employees within the order centres. The degrees of goal achievement of lead time and work in progress rise significantly by more than $15 \%$. Even lead time deviation and utilization increase remarkably. Regarding the utilization this improvement implies a higher dynamic capacity of the system. This fact is supported by the results of [5, p. 137], who stated a dynamic capacity of about $92 \%$ for an object-oriented form of organizational structure. However, this value cannot be achieved by variation 4 , because object-orientation is realized here not in a strict way implying an organizational unit for each order type: Due to the allocation of several order types to one organizational unit, the possibility of disturbances during the order processing increases.

\section{CONCLUSIONS AND FURTHER DEVELOPMENTS}

This study shows the suitability of simulation tools for the evaluation of the organizational performance in production systems. Apart from controlling, branch comparison and benchmarking, simulation is one possible approach to estimate the position of an enterprise in the market and to reveal possible further improvements. The advantages of this approach are as follows: No information from other companies is needed and data regarding only the own production system has to be collected. In search for improvements only theoretical restrictions limit possible solutions. But, realistic boundaries of improvements are hard to define.

Therefore, neither simulation nor benchmarking represents the only solution of the problem. Both approaches should be used in parallel. Information on good solutions for the processing of certain tasks which have already been realized can only be achieved by analyzing these processes in other companies, if possible. The idea of benchmarking is based upon the discovery of such successful processes.

In order to estimate the performance of an enterprise, different independent indicators should be used. Otherwise the danger of deteriorating the performance of an entire system can emerge. A single indicator or dependent indicators cannot consider the complexity of a production system in an adequate manner. Consequently, a simulation aided procedure seems to be a suitable concept for the evaluation of production systems because this approach fulfills the requirements of a comprehensive analysis.

\section{REFERENCES}

1. Zülch, Gert; Grobel, Thomas: Simulating Organizational Structures. In: Production Planning \& Control, London, 4(1993)2, pp. 128-138.

2. VDMA - Verband Deutscher Maschinen- und Anlagenbau, Abteilung Betriebswirtschaft (Ed.): Kennzahlenkompaß. Frankfurt/M.: Maschinenbau, 1992.

3. Spendolini, Michael J.: The Benchmarking Book. New York: Amacom, 1992.

4. Wedemeyer, Hans-Georg von: Entscheidungsunterstützung in der Fertigungssteuerung mit Hilfe der Simulation. Düsseldorf: VDI, 1989. (Fortschritt-Berichte VDI, Reihe 2, Nr. 176)

5. Grobel, Thomas: Analyse der Einflüsse auf die Aufbauorganisation von Produktionssystemen. University of Karlsruhe, Diss. 1993. (ifab Schriftenreihe des Instituts für Arbeitswissenschaft und Betriebsorganisation der Universităt Karlsruhe, Band 6, ISSN 0940-0559)

6. Weck, Manfred (Ed.): Simulation in CIM. Berlin u.a.: Springer; Köln: TÜV Rheinland, 1991. (Reihe CIM-Fachmann) 
7. Schulte, Helmut; Stanek, Werner; Wirth, Siegfried: Ganzheitliche Unternehmensplanung. In: Zeitschrift für wirtschaftliche Fertigung und Automatisierung, München, 86(1991)7, pp. 328-331.

8. Fryer, John S.: Organizational Segmentation and Labor Transfer Policies in Labor and Machine Limited Production Systems. In: Decision Sciences, Atlanta GA, 7(1976)4, pp. 725-738.

9. Sculli, Dominic: Priority Dispatching Rules in an Assembly Shop. In: Omega, Oxford, 15(1987)1, pp. 49-57.

10. Augustin, Siegfried; Jahn, Siegfried: Entwicklungslogistik: Der Weg zum schnellen "timeto-market". In: Logistik-Synergie zwischen Handel und Industrie. Ed: Bäck, Herbert. Köln: TÜV Rheinland, 1990, pp. 7-17.

11. Baker, Kenneth R.: Sequencion Rules and Due-Date Assignment in a Job Shop. In: Management Science, Baltimore MD, 30(1984)9, pp. 1093-1103.

12. Adam, Nabil R.; Bertrand, J. Will M.; Surkis, Julius: Priority Assignment Procedures in Multi-Level Assembly Job Shops. In: IEE Transactions, Norcross GA, 19(1987)3, pp. 317328.

13. Dar-El, Ezey M.; Wysk, Richard A.: Job Shop Scheduling - A Systematic Approach. In: Journal of Manufacturing Systems, Dearborn MI, 1(1982)1, pp. 77-88.

14. Goodwin, Jack S.; Goodwin, James C.: Operating Policies for Scheduling Assembled Products. In: Decision Sciences, Atlanta GA, 13(1982)5, pp. 585-603.

15. Grünwald, H.; Striekwold, P.E.T.; Weeda, P.J.: A Framework for Quantitative Comparison of Production Control Concepts. In: International Journal of Production Research, London, 27(1989)2, pp. 281-292.

16. Amon, Markus: Instandhaltungs-Controlling mit Kennzahlen. In: REFA-Nachrichten, Darmstadt, 44(1991)1, pp. 17-20.

17. Grobel, Thomas: Simulation der Organisation rechnerintegrierter Produktionssysteme. University of Karlsruhe: Institut für Arbeitswissenschaft und Betriebsorganisation, 1992. (ifab Schriftenreihe des Instituts für Arbeitswissenschaft und Betriebsorganisation der Universităt Karlsruhe, Band 3, ISSN 0940-0559)

18. Graf, Karl-Robert: Systematische Untersuchung von Einflußgrößen einer Fertigungssteuerung nach dem Zieh- und Schiebeprinzip. University of Karlsruhe, Diss. 1991. (ifab Schriftenreihe des Instituts für Arbeitswissenschaft und Betriebsorganisation der Universität Karlsruhe, Band 2, ISSN 0940-0559)

19. Zülch, Gert; Grobel, Thomas: Simulating the Departmental Organization for Production to Order. In: 'One-of-a-kind' Production: New Approaches. Eds.: Hirsch, B.; Thoben, K.-D. Amsterdam u.a.: North Holland, 1992, pp. 177-193. (IFIP Transactions B: Applications in Technology, B-2)

20. REFA - Verband für Arbeitsstudien und Betriebsorganisation (Ed.): Planung und Steuerung. Part 2: Chapter 5-9. München: Hanser, 1991. (Methodenlehre der Betriebsorganisation).

21. Grobel, Thomas: Influences on the Organizational Structure of Production Systems. In: Human Factors in Organizational Design and Management. Ed.: Bradley, Gunilla; Hendrick, Hal. Amsterdam u.a.: North-Holland, 1994, pp. 29-36.

22. Zülch, Gert; Grobel, Thomas: Shaping the Organization of Order Processing With the Simulation Tool FEMOS. In: 8th Working Seminar on Production Economics. Pre-prints. Volume 1. Hrsg.: Grubbström, R.W.; Hinterhuber, H.H.; Lundquist, J. u.a. Igls, 1994, S. 319-332.

23. Zülch, Gert; Grobel, Thomas: Suitability of Selected Strategies of Production Control. In: Advances in Production Management Systems. Eds.: Pappas, I.A.; Tatsiopoulos, I.P. Amsterdam u.a.: North-Holland, 1993, pp. 313-321. 